\title{
One Big Happy Engineering Family? The Influence OF Psychological Contracts on Team OUTCOMES AND The Mediating Role of Person-Team Fit
}

\author{
Katherine Gibbard ${ }^{1}$, Yannick Griep ${ }^{1,2}$, Genevieve Hoffart ${ }^{1}$, and Denis Onen ${ }^{3}$ \\ ${ }^{1}$ Department of Psychology, The University of Calgary, ${ }^{2}$ Division of Epidemiology, Stress Research Center, Stockholm \\ University, ${ }^{3}$ The Schulich School of Engineering, The University of Calgary \\ kgibbard@ucalgary.ca
}

\begin{abstract}
Teamwork is frequently used to tackle complex and demanding tasks in organizational and educational settings. While teamwork may offer substantial benefits, the challenges of working effectively in teams are considerable. This study examines the roles of psychological contract breach and person-team fit in relation to teams' effectiveness. Twelve teams of electrical and computer engineering students were surveyed at three time points to assess their perceptions of personteam fit and psychological contract breach.

Results of a longitudinal mediation model supported our hypotheses that team level psychological contract breach would result in decreased supplementary fit and increased complementary fit. Regarding team outcomes, we found that perceptions of supplementary fit increased team member peer feedback ratings, while perceptions of complementary fit increased team potency. Follow-up analyses revealed that psychological safety was positively related to psychological contract breach. Implications for practice are discussed.
\end{abstract}

Keywords: person-team fit, psychological contract breach, team performance, team potency, supplementary personteam fit, complementary person-team fit, time.

\section{INTRODUCTION}

In today's economic reality, coloured by a range of organizational changes, downsizing, restructuring, layoffs, and rapidly changing market needs, organizations need to constantly adapt to remain competitive and innovative. This evolution has given rise to greater reliance on teams to draw from the expertise of multiple individuals in an attempt to generate innovative solutions and produce results superior to what individual members would have accomplished independently [1]. However, along the path to high performance, teams may encounter setbacks, such as team conflict, that impinge upon their ultimate goal of producing high quality and innovative work [2]. Although scholars are aware of the factors that may result in such setbacks, teams often still fail to reach their full potential [3]. With the knowledge that teamwork is not always associated with higher performance, we draw from Laulié and Tekleab's [4] Multi-Level Theory of Psychological Contracts and Brewer's [5] Optimal Distinctiveness Theory to study perceptions of psychological contract breach at the team level in relation to team members' perceptions of person-team fit to explain a team's success or failure.

Psychological contracts (PC) are traditionally defined as "an individual's beliefs regarding the terms and conditions of a reciprocal exchange agreement between that focal person and another party" [6]. PC breach occurs when individuals perceive that their employer does not meet one or more obligations at specific points in time [6]. Although the vast majority of $\mathrm{PC}$ research has centered on perceptions of $\mathrm{PC}$ breach at the individual level, recent theoretical work has proposed the concept of team PC breach to understand how team PC fulfillment or breach relates to team performance [4].

Although PC theory has traditionally been used to understand the mutual and reciprocal obligations in the employee-employer relationship, the seminal conceptualization of PC theory [6] already acknowledged that groups of individuals can develop a shared nonwritten agreement with their organization. Laulié and Tekleab [4] recently developed a Multi-Level Theory of Psychological Contracts which puts forth propositions on how perceptions of PC fulfillment and breach can be explained by social phenomena and continuous interactions among employees who work closely together (i.e., teams). Specifically, Laulié and Tekleab [4] introduce and differentiate two types of team-level PC constructs: shared team PCs and shared individual PCs. The former is defined as "the convergence of team members' perception of the degree of fulfillment or breach of the obligations that an organization promised to the team" [4] whereas the latter is defined as "the convergence of team members' perception of the degree 
to which employers fulfill or breach their own individual psychological contracts" [4]. Note that although the theoretical arguments for the emergence of both constructs are similar, they are conceptually and operationally different from each other because the shared team PC deals with an aggregate of all team members' perceptions of team PC fulfillment or breach, whereas the shared individual PC deals with an aggregate of all team members' perceptions of their own PC fulfillment or breach.

In the remainder of the paper, we will focus on shared team PC breach as an aggregate of all team members' perceptions of PC breach because we were interested in understanding how the obligations team members believed they had toward the team were fulfilled or breached and how these shared team perceptions about PC breach influenced team performance.

While person-team fit has previously been conceptualized simply as congruence between the team and the individual [7], recent work has stressed the differentiation between two types of person-team fit: complementary fit and supplementary fit [8]. De Cooman and colleagues [8] have described complementary fit as an individual's characteristics that are unique additions to the team, while they refer to supplementary fit as an individual's characteristics that are similar to the team. In the event of PC breach, these fit types may be impacted differentially. Drawing upon Optimal Distinctiveness Theory [5] we argue that individuals are driven to reach an equilibrium between similarity and distinctiveness from their team. Specifically, we argue that a team member who experiences a team PC breach will decrease his/her drive to be similar to the team (i.e., supplementary fit), while simultaneously increasing the drive to be distinct from the team (i.e., complementary fit), stemming from a desire to reduce perceived affiliation with a team that has violated a PC. Past research supports that when PC breaches occur, employees experience decreased person-organization fit [9]. Therefore, we hypothesize:

Hypothesis 1a: Team members' perceptions of psychological contract breach will be negatively related to team members' perceptions of supplementary personteam fit.

Hypothesis 1b: Team members' perceptions of psychological contract breach will be positively related to team members' perceptions of complementary personteam fit.

Team potency is defined as a group's belief that they can be effective [10]. It is the best measure of team performance in the absence of direct performance outcomes [11]. In this study team potency is used in lieu of grades.

Teams with greater complementary fit are perceived as more diverse, whether that be in terms of team members' knowledge, skills, abilities, or beliefs. The psychological process that underlies complementary fit is need fulfillment [12], which occurs when an individual's strength can compensate for a weakness in the environment (e.g., the team), and vice versa [13]. Research has demonstrated that perceptions of complementary fit contribute positively to job satisfaction, affective commitment, and turnover intentions [14].

Teams with a wider base of functional diversity (i.e., teams with varied areas of expertise or specialization) have been found to perform better [15]. When a team is faced with a complex, multifaceted problem, having a diverse pool of knowledge to draw upon (i.e., high perceptions of complementary person-team fit) may be beneficial for performance. As a consequence, these team members will believe that they have more diverse functional backgrounds and bring unique additions to the team, which might increase team performance [15]. As such, we hypothesize:

Hypothesis 2: Team members' perceptions of complementary person-team fit will be positively related to team potency.

The underlying theoretical basis of supplementary fit is the similarity-attraction paradigm [16], which states that a team member is more likely to be attracted to and like other team members who are more similar to themselves because these relationships are believed to be more rewarding and supportive [16]. Several empirical studies indeed support this idea by demonstrating a positive relationship between perceived supplementary person-team fit and co-worker satisfaction, team cohesion, general satisfaction, organizational commitment, organizational citizenship behaviors and a negative relationship with turnover intensions [13]. As such, perceptions of supplementary person-team fit may increase positive perceptions of the team's functioning, as would be evident in the team's ratings of their dynamics [15] and positive attitudes towards the team [17].

Hypothesis 3: Team members' perceptions of supplementary person-team fit will be positively related to team peer feedback ratings.

\section{METHOD}

\subsection{Participants}

We collected multiple-wave data during a 12-week long team project in a group of 66 electrical and computer engineering students who participated in a course on electrical engineering design and technical communications at the University of Calgary. In total, 47 students comprising 12 teams consented to have their responses included in this study. Most participating students were in the third year of their four-year curriculum. During the second week of the semester students were divided into project teams with four to six 
members who collaborated intensively. The project involved solving a real-world engineering problem and creating a prototype. Students were required to follow a rigorous engineering design process, which involved developing a concept, engaging in project management, testing their prototype, writing technical documentation, and presenting the project. This project was worth $87 \%$ of students' overall grade.

\subsection{Procedure}

For this study we collected three waves of data via paper and pencil surveys (i.e. first wave) and our own online survey platform ITP Metrics, itpmetrics.com (i.e. second and third wave). In all three waves of data collection we asked the students to report on their perceptions of PC breach, supplementary and complementary fit, and perceived team potency. The first wave of data collection happened one week after group formation, the second wave of data collection happened four weeks after group formation, and the last wave of data collection coincided with the termination of the project.

\subsection{Measures}

Perceived PC breach was measured using Vantilborgh, Bidee, Pepermans, Griep, and Hofmans' [18] direct measure of PC breach. In particular, we presented respondents with a graphical rating scale for each team member (i.e. number of rating scales equals the number of team members) and asked them to indicate to what extent each team member had fulfilled or breached his/her obligations to the team. This graphical scale had three anchors: 1) $-50=$ did far less than what was obligated; 2) $0=$ did exactly what was obligated; and 3) $+50=$ did far more than what was obligated. By doing so, we followed Fisher and To' s [19] recommendation to use a large number of response options when single item measures are used. Cross-validation of this single item by Vantilborgh and colleagues [18] indicated that this scale correlated significantly and in the expected direction with a longer scale by Tekleab and Taylor [20].

Perceived person-team fit was measured using Piasentin and Chapman's [14] multidimensional measure of perceived fit. This measure consists of 17 items: nine items to assess supplementary person-team fit and eight items to assess complementary person-team fit. An example item of complementary person-team fit is "My team members rely on me because I have competences that they do not have," whereas an example item of supplementary person-team fit is "My skills and abilities match the skills and abilities this team looks for in team members." We slightly adjusted the wording of the items to better capture the person-team fit instead of the personorganization fit. Specifically, we changed the words "employees or coworkers" into "team members" and changed the words "organization or company" into "team." We asked our participants to rate all items on a 7point Likert scale ranging from (1) "Strongly disagree" to (7) "Strongly agree." Reliabilities were satisfactory at all three measurement points.

Team performance was operationalized as team potency (i.e. belief that a team can be effective), which is the best subjective measure of performance [11]. An example item is "Our team believes it can solve any problem it encounters." Participants responded to four statements on team potency on a 5-point Likert scale ranging from (1) "Strongly disagree" to (5) "Strongly agree." Reliabilities were satisfactory at all three measurement points.

Peer feedback ratings were evaluations of team member's abilities on five competencies that have been found to be of critical importance for team effectiveness. The five competencies are: 1) Commitment to the team's work; 2) Communicating with team members; 3) Having a strong foundation of knowledge, skills and abilities; 4) Emphasizing high standards; and 5) Keeping the team on track [21]. Each of the five competencies included detailed descriptions beneath them and participants were asked to rate each competency for each of their fellow teammates. We asked our participants to rate all items on a 5-point Likert scale ranging from (1) "To no extent" to (5) "To a great extent." Reliabilities were satisfactory at all three measurement points.

\subsection{Analyses}

The three-wave longitudinal data allowed us to examine whether there was evidence for the hypothesized temporal precedence (i.e. one of the important conditions of causality) in the relationship between team members' perceptions of PC breach and team performance (i.e. potency and peer feedback ratings) via perceptions of supplementary and complementary person-team fit. Hence, we analysed our data by means of a longitudinal three-wave mediation model $[22,23]$ using Mplus version 7.1 [24] in which we controlled for change by means of including the autoregressive effects (i.e., the correlation between a variable and itself over time).

\section{RESULTS}

As expected we found that team perceptions of PC breach at time 1 decreased supplementary fit at time 2, while increasing complementary fit at time 2 in both models. Therefore, both hypothesis $1 \mathrm{a}$ and $1 \mathrm{~b}$ were supported.

Turning to hypothesis 2 we found that perceptions of complementary fit at time 2 increased team potency at time 3 (Fig. 1). 


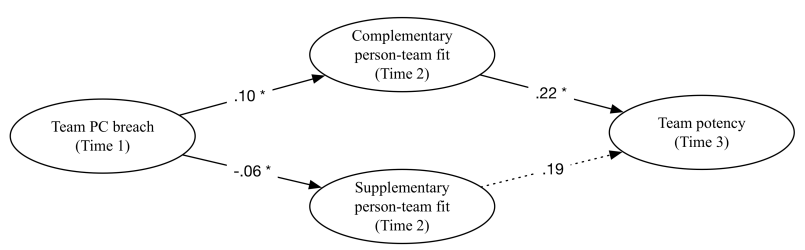

Fig. 1. Path estimates for the relationship between team $\mathrm{PC}$ breach and team potency as mediated by fit type. ${ }^{*} p<.05$

Moreover, we found that perceptions of supplementary fit at time 2 increased team member ratings of peer feedback at time 3 (see Fig. 2).

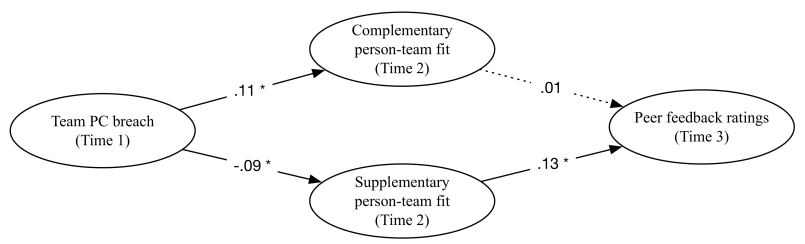

Fig. 2. Path estimates for the relationship between team contract fulfilment and peer feedback ratings as mediated

${ }^{*} p<.05$ by fit type.

Additional follow-up analyses revealed that psychological safety at one point in time was positively related to team members' perceptions of PC breach at the next point in time. This finding seems to suggest that in teams where members felt safe to take interpersonal risks, they also felt safe to report that a team PC breach had occurred.

\section{DISCUSSION}

PC breach at the team level is a relatively new and understudied construct. Our results delineate the relationship between team level PC breach and supplementary and complementary fit types. Previous person-team fit theories could presume that PC breach would decrease fit overall because the theories did not take into account the distinction between supplementary and complementary fit. However, our findings indicate that PC breach impacts supplementary fit and complementary fit differently. This aligns with Brewer's Optimal Distinctiveness Theory [5], in which individuals strive to strike a balance between being unique within the team and being similar to the team.

Our results also support the predicted impact of supplementary and complementary fit on different performance related outcomes, namely team potency and peer feedback ratings. As past work would lead us to believe, supplementary fit was found to be important for positive perceptions of one's team or social group [13]. This aligns with the similarity-attraction paradigm [16].
While this explains why team members would be inclined to rate each other more highly, what is arguably of greater importance is the actual performance outcome of the team. Based on our findings, complementary fit is predictive of team potency. This finding lends support to the teaching practice of creating student teams that are more heterogeneous. Teams with members who have varied skills and opinions may benefit from this diversity and experience increases in performance.

Indeed, differences in opinion can lead to positive outcomes. Constructive controversy occurs when individuals have incompatible ideas or opinions, yet they seek to reach consensus [25]. In instances where there is a clear and cooperative goal to pursue (e.g. a large class project), members are motivated to succeed by minimizing harmful conflict, while also striving to find the best possible path forward. Constructive controversy serves these situations well. Research has found that constructive controversy results in higher quality decisions and solutions $[25,26]$. Specific guidelines have been proposed and validated to help teams engage in constructive controversy, including a detailed procedure that can be taught to students $[25,26]$. The implication of these findings when taken with the findings of the current study is that in teams with greater complementary fit, constructive controversy training could be implemented to scaffold this process and further enable teams to benefit from the diversity of their members.

Follow-up analyses found that psychological safety was positively related to PC breach. This suggests that individuals who feel comfortable sharing their honest opinions within the team are more likely to admit that a PC breach had occurred [27]. Psychological safety can increase instances of interpersonally risky learning behavior, such as help seeking and discussion of errors [28]. Members of teams characterized by high scores on psychological safety are able to more honestly appraise a negative team experience like PC breach and report it. There is empirical support for this association between psychological safety and reporting negative events. For example, Edmondson [27] found that high performing teams reported higher error rates than lower performing teams. However, this wasn't due to the higher performing teams making more errors - it was due to the higher performing teams feeling safe to admit to their errors. In other words, these teams had higher levels of psychological safety, which allowed them to openly admit their failings. Our finding suggests that teams should strive to foster a psychologically safe environment where team members feel comfortable to honestly evaluate the team's PC breaches. Edmondson [29] names three key ways to promote psychological safety in teams:

1. Frame work as a learning problem, as opposed to an execution problem [29]. This suggestion highlights that team members should acknowledge that what's to come is uncertain and that they need 
contributions from the whole team to manage the ensuing uncertainty.

2. Acknowledge your own fallibility [29]. Edmondson suggests that team members make statements that allow team mates to speak up and address potential errors.

3. Model curiosity [29]. This recommendation emphasizes the importance of continuing to ask questions and engage in an active dialogue.

Additionally, psychological safety in itself has been tied to increased performance [27]. Thus, fostering psychological safety in teams should help address negative events like PC breach and also has the potential to increase performance.

\section{CONCLUSION}

This study sought to better understand the impact of PC breach on team outcomes, as mediated by complementary and supplementary person-team fit. Data was collected at three time points over the course of a 12week long team project in an upper year electrical engineering course. Students worked intensively on an applied project in teams of four to six. Our results showed that PC breaches within these teams impacted perceived supplementary person-team fit differently from perceived complementary person-team fit. Additionally, supplementary fit proved important for team member peer ratings while complementary fit was found to be positively related to team potency. The practical implications of this finding supports the creation of work teams whose members are diverse and who present with skill sets that are unique within their teams. Additionally, our follow-up analyses revealed that psychological safety was an antecedent to PC breach. Educators should emphasize the importance of psychologically-safe environments for optimal team outcomes.

\section{Acknowledgements}

Special thanks to Alyssa Grocutt, a research assistant from the Individual and Team Performance lab, who contributed invaluable time and energy to survey data entry.

\section{References}

[1] Doris Fay, Helen Shipton, Michael A. West, and Malcolm Patterson, "Teamwork and organizational innovation: The moderating role of the HRM context," Creativity and Innovation Management, vol. 24, no. 2, pp. 261-277, 2015. Available as of December 2014 from http://irep.ntu.ac.uk/id/eprint/5823/1/PubSub2318_Shipton.p df
[2] Thomas A. O'Neill, Natalie J. Allen, and Stephanie E. Hastings, "Examining the "Pros" and "Cons" of team conflict: A team-level meta-analysis of task, relationship, and process conflict," Human Performance, vol. 26, no. 3, pp. 236-260, 2013.

[3] Eduardo Salas, Gerald Goodwin, and C. Shawn Burke, Team Effectiveness in Complex Organizations: Cross-Disciplinary Perspectives and Approaches. New York, NY: Routledge, 2008, 589 pp. \{ISBN: 978-0-8058-5881-5\}

[4] Lyonel Laulié, and Amanuel G. Tekleab, “A multi-level theory of psychological contract fulfillment in teams," Group \& Organization Management, vol. 41, no. 5, pp. 658-698, 2016.

[5] Marilynn B. Brewer, "The social self: On being the same and different at the same time," Personality and Social Psychology Bulletin, vol. 17, no. 5, pp. 475-482, 1991. Available as of October 1991 from http://web.mit.edu/curhan/www/docs/Articles/15341_Readi ngs/Intergroup_Conflict/Brewer_1991_The_social_self.pdf

[6] Denise M. Rousseau, "Psychological and implied contracts in organizations," Employee Responsibilities and Rights Journal, vol. 2, no. 2, pp. 121-139, 1989. Available as of June 1989 from

https://www.researchgate.net/profile/Denise_Rousseau/publi cation/226857215_Psychological_and_Implied_Contracts_i n_Organisations/links/5424bc220cf238c6ea73b6ad.pdf

[7] Amy Kristof-Brown and Russell P. Guay, "Personenvironment fit," in APA Handbook of Industrial and Organizational Psychology, Sheldon Zedeck (ed.), 48 pp., 2011.

[8] Rein De Cooman, Tim Vantilborgh, Matthijs Bal, and Xander Lub, "Creating inclusive teams through perceptions of supplementary and complementary person-team fit: Examining the relationship between person-team fit and team effectiveness," Group and Organization Management, vol. 41, no. 3, pp. 310-342, 2016. Available as of June 4, 2015 from http://journals.sagepub.com/doi/full/10.1177/105960111558 6910

[9] Carol C. Bocchino, Bruce W. Hartman, and Pamela F. Foley, "The relationship between person-organization congruence, perceived violations of the psychological contract, and occupational stress symptoms," Consulting Psychology Journal, vol. 55, no. 4, pp. 203-214. Available as of Fall 2003

from https://www.researchgate.net/profile/Pamela_Foley/publicati on/232556086 The Relationship_Between Person-

Organization_Congruence Perceived Violations of the Ps ychological_Contract_and_Occupational_Stress_Symptoms/ links/552ee $\overline{7}$ a00cf2acd38cbbda28.pdf

[10] Richard A. Guzzo, Paul R. Yost, Richard J. Campbell, and Gregory P. Shea, "Potency in groups: Articulating a construct," British Journal of Social Psychology, vol. 32, no. 1, pp. 87-106, 1993. 
[11] John J. Sosik, Bruce J. Avolio, and Surinder S. Kahai, "Effects of leadership style and anonymity on group potency and effectiveness in a group decision support system environment," Journal of Applied Psychology, vol. 82, no. 1, pp. 89-103, 1997.

[12] Jeffrey R. Edwards, Person-job fit: A conceptual integration, literature review, and methodological critique. In Cary L. Cooper and Ivan T. Robertson (eds.), International Review of Industrial and Organizational Psychology. Chichester, UK: Wiley, 1991, 74 pp.

[13] Amy L. Kristof-Brown, Ryan D. Zimmerman, and Erin C. Johnson, "Consequences of individuals' fit at work: A metaanalysis of person-job, person-organization, person-group, and person-supervisor fit," Personnel Psychology, vol. 58, no. 2, pp. 281-342, 2005. Available as of May 9, 2005 from http://nreilly.asp.radford.edu/kristof-brown\%20et\%20al.pdf

[14] Kelly A. Piasentin, and Derek S. Chapman, "Perceived similarity and complementarity as predictors of subjective person-organization fit," Journal of Occupational and Organizational Psychology, vol. 80, no. 2, pp. 341-354, 2007. Available as of June 2007 from http://s3.amazonaws.com/academia.edu.documents/4333808 5/Perceived_similarity_and_complementarity201603032528tw38p5.pdf?AWSAccessKeyId=AKIAIWOWYYGZ2Y53U L3A\&Expires $=1493499003 \&$ Signature $=$ DvPxltbXp\%2BwX JwDppu7oHNaUw\%2BA\%3D\&response-contentdisposition $=$ inline $\% 3 \mathrm{~B} \% 20$ filename $\% 3$ DPerceived similarit y_and_complementarity.pdf

[15] Suzanne T. Bell, Anton J. Villado, Marc A. Lukasik, Larisa Belau, and Andrea L. Briggs, "Getting specific about demographic diversity variable and team performance relationships: A meta-analysis," Journal of Management, vol. 37, no. 3, pp. 709-743, 2011. Available as of September 1, 2010 from http://journals.sagepub.com/doi/pdf/10.1177/014920631036 5001

[16] Donn Byrne, "Attitudes and attraction," Advances in Experimental Social Psychology, vol. 4, pp. 35-89, 1969.

[17] Amy L. Kristof-Brown, Murray R. Barrick, and Cynthia Kay Stevens, "When opposites attract: A multi-sample demonstration of complementary person-team fit on extraversion," Journal of Personality, vol. 73, no. 4, pp. 935-958, 2005. Available as of May 4, 2005 from http://www.sitesbysarah.com/mbwp/Pubs/2005_KristofBrown_Barrick_Stevens_JOP.pdf

[18] Tim Vantilborgh, Jemima Bidee, Roland Pepermans, Yannick Griep, and Joeri Hofmans, "Antecedents of psychological contract breach: The role of job demands, job resources, and affect. PloS one, vol. 11, no. 5, pp. 1-22, 2016. Available as of May 12, 2016 from http://journals.plos.org/plosone/article/file?id=10.1371/journ al.pone. $0154696 \&$ type $=$ printable
[19] Cynthia D. Fisher, and March L. To, "Using experience sampling methodology in organizational behavior," Journal of Organizational Behavior, vol. 33 no. 7,pp. 865-877, 2012. Available as of June 1, 2012 from https://www.researchgate.net/profile/Cynthia_Fisher2/public ation/228079821_Using_experience_sampling_methodolog $\mathrm{y}$ in organizational behavior/links/55ee4ebe08ae199d47be ef97.pdf

[20] Amanuel G. Tekleab, and M. Susan Taylor, "Aren't there two parties in an employment relationship? Antecedents and consequences of organization-employee agreement on contract obligations and violations," Journal of Organizational Behavior, vol. 24, no. 5, pp. 585-608, 2003.

[21] Misty L. Loughry, Matthew W. Ohland, and D. DeWayne Moore, "Development of a theory-based assessment of team member effectiveness," Educational and Psychological Measurement, vol. 67, no. 3, pp. 505-524, 2007. Available as of September 17, 2016 from http://citeseerx.ist.psu.edu/viewdoc/download?doi=10.1.1.10 $13.1932 \&$ rep $=$ rep $1 \&$ type $=$ pdf

[22] David Cole and Scott E. Maxwell, "Testing mediational models with longitudinal data: Questions and tips in the use of structural equation modeling," Journal of Abnormal Psychology, vol. 112, no. 4, pp. 558-577, 2003.

[23] David P. MacKinnon, Introduction to Statistical Mediation Analysis. New York, NY: Routledge, 2008, 473 pp.

[24] Linda K. Muthén and Bengt O. Muthén, Mplus User's Guide Los Angeles, CA: Muthén \& Muthén, 2013 ( $7^{\text {th }}$ ed.).

[25] David W. Johnson, Roger T. Johnson, and Karl A. Smith, "Constructive controversy: The educative power of intellectual conflict," Change: The Magazine of Higher Learning, vol. 32, no. 1, pp. 28-37, 2010. Available as of March 25 from http://www.tandfonline.com/doi/pdf/10.1080/000913800096 02706

[26] Thomas A. O'Neill, Genevieve Hoffart, Matthew McLarnon, Hayden Woodley, and Natalie Allen, "Constructive controversy and reflexivity training promotes effective conflict profiles and outcomes in student learning teams," Academy of Management Learning and Education.

[27] Amy Edmondson, "Psychological safety and learning behavior in work teams," Administrative Science Quarterly, vol. 44, no. 2, pp. 350-383, 1999. Available as of June 1999 from http://www.iacmr.org/v2/Conferences/WS2011/Submission XM/Participant/Readings/Lecture9B Jing/Edmondson,\%2 0ASQ\%201999.pdf

[28] Amy C. Edmondson, Managing the Risk of Learning: Psychological Safety in Work Teams. Boston, MA: Division of Research, Harvard Business School, 2002, 38 pp.

[29] Shana Lebowitz, Google Considers this to be the Most Critical Trait of Successful Teams. Business Insider, 2015.

CEEA17; Paper 001

University of Toronto; June 4-7, 2017 
Available as of November 20, 2015 from http://www.businessinsider.com/amy-edmondson-onpsychological-safety-2015-11 